Bol. Acad. peru. leng. 62.2017 (147-169)

\title{
Escritura y género en los Comentarios reales
}

\section{Writing and Gender in the Royal Commentaries}

\author{
RaQuel Chang-Rodríguez \\ City College-Graduate Center, City University of New York
}

Resumen:

Comentarios reales (1. a parte, $1609 ; 2{ }^{\text {a }}$ parte, 1617$)$, del cronista cuzqueño Inca Garcilaso de la Vega (1539-1616), es una obra clave en la historia literaria y cultural de las Américas y del mundo hispánico. Si bien la crónica ha sido estudiada desde diferentes perspectivas disciplinarias, se ha prestado poca atención a la función del género en su desarrollo. Este ensayo destacará cómo el Inca Garcilaso entremezcla en el curso de la narración, actos y eventos relacionados con su madre, la palla Chimpu Ocllo. Propongo que las viñetas en las cuales predomina su presencia contribuyen a conformar la singular reinterpretación de la historia del virreinato peruano evidente en Comentarios reales, marcándola con un matiz de género frecuentemente desapercibido.

\section{Abstract:}

Comentarios reales (1st part, 1609; 2nd part, 1617) by the Cuzcan chronicler Inca Garcilaso de la Vega (15391616), is a key work in the literary and cultural history 
of America and the Hispanic world. Although the chronicle has been studied from different disciplinary perspectives, less attention has been paid to the function of gender. This essay emphasizes how Inca Garcilaso intertwined in his narration, events and deeds related to his mother, palla Chimpu Ocllo. It proposes that episodes marked by her presence contribute to shape a more nuanced reinterpretation of Peruvian history, now marked by the presence of gender.

Palabras clave: género, palla, incas, Chimpu Ocllo, Atahualpa, Inca Garcilaso.

Keywords: gender, palla (princess), Incas, Chimpu Ocllo, Atahualpa, Inca Garcilaso.

Recibido: 24/09/2016

Aceptado: 15/04/2017

La presencia del padre del autor, el capitán Sebastián Garcilaso de la Vega, en la segunda parte de Comentarios reales es notoria y significativa; baste recordar la oración a su muerte por un anónimo sacerdote recogida por el enlutado hijo en el libro 8, capítulo 12 de esa obra. Aparentemente la presencia de la madre no tiene igual dimensión en ninguna de las dos partes de la obra maestra del luminar cuzqueño. Quizá por ello en un ensayo de 1994 don Aurelio Miró Quesada reparó en la brevedad del «retrato escrito» de la progenitora del Inca Garcilaso y en cómo la palla desfila «como una 
sombra» por la obra maestra del hijo (1994: 353)1. Si bien tuvo razón el ilustre garcilasista cuando destacó la opacidad de su presencia, el repaso de algunas de estas instancias permite vislumbrar cómo esa «sombra» se perfila cuando el narrador, por medio de la evocación y la acción, la imbrica en la estructura de Comentarios reales. En este ensayo me propongo acudir a las referencias a la madre, unas fugaces, otras más evidentes, para proponer que, por medio de estas alusiones donde se mezcla el relato de las acciones y la evocación de la persona de Chimpu Ocllo, bautizada Isabel Suárez, el cronista trasciende la adversidad, critica el coloniaje, rememora las glorias del incario y trae a colación las luchas fratricidas presagiadoras de su fin².

La madre le otorga al autor el vínculo con la élite incaica - en particular la panaca ${ }^{3}$ o aillu real de Túpac Inca Yupanqui- del cual se jacta en sus escritos; tal conexión igualmente lo liga al sino desdichado de la estirpe representado en las luchas entre Huáscar y Atahualpa, el asesinato del primero, la matanza de mujeres y niños de la sangre real de parte del segundo y la pérdida del incario. De esta forma la presencia materna tanto como su genealogía se implican de un modo $\mathrm{u}$ otro en la estructura profunda y el significado de Comentarios reales. Desde la primera parte de la crónica, las menciones a Chimpu Ocllo y su estirpe contribuyen

1 Más recientemente Mercedes López-Baralt (2011: 18, Nº 1; 260-261) ha observado que el Inca desdibujó a su madre en Comentarios reales. Max Hernández se aproximó a la palla por medio del psicoanálisis (1993).

2 Para una ampliación de este y otros temas ver Chang-Rodríguez (2013).

3 Si bien el término ha sido cuestionado (Hernández Astete 2008, Itier 2011), por su frecuencia lo incluimos aquí para referirnos a los aillus reales y su descendencia. 
a marcar el discurso garcilasista con un sesgo trágico; paralelamente, muestran la óptima calidad del clan materno y por ende del autor. Encontramos la evocación o comparecencia de la figura de la progenitora en anécdotas curiosas y en el relato de sucesos donde su presencia cataliza la acción o promueve la reflexión de parte del lector.

\section{La voz de la madre}

El más importante de estos segmentos figura en el capítulo quince del primer libro de Comentarios reales. Allí el narrador sienta las bases de la crónica cuando explica cómo pondrá orden al gran «labirinto» de la historia de los «Incas Reyes naturales que fueron del Perú». Los relatos de los parientes —en particular de la madre y de su tío Cusi Huallpa-, que Gómez Suárez escuchó cuando era niño y adolescente, se constituyen en la brújula de la narración: «el camino más fácil y llano era contar lo que en mis niñezes oí muchas vezes a mi madre y a sus hermanos y tíos y a otros sus mayores acerca deste origen y principio» ${ }^{4}$. Ese pasado debe difundirse "por las propias palabras que los Incas lo cuentan que no por las de otros autores estraños» $(C R, 1$, libro 1, cap. 15, 39).

Las pláticas - o sea, la oralidad- en las cuales se fundamenta la obra maestra de Garcilaso, ocurren en la casa materna y se suscitan semanalmente, en el transcurso de varios años, entre pallas e incas, entre Chimpu Ocllo y los familiares sobrevivientes de las crueldades

4 Cito por la edición de Ángel Rosenblat. 
de Atahualpa, entre Gómez Suárez y todos ellos ${ }^{5}$. Siguiendo a Uspenski (1973), se incorpora así a la narración la perspectiva discursiva o fraseológica y también la ideológica. La primera marca el discurso de acuerdo con el tipo de narrador y su punto de vista, mientras la segunda ofrece la visión conceptual de ese mundo ya en un segmento de la historia, ya en su totalidad. De este modo la noción de punto de vista se entiende tanto en su acepción técnica, como en el significado de mirador desde el cual se condiciona la representación, sustentada por el sistema de juicios y valores donde se asienta una particular visión del mundo descrito: en este caso, la incaica, observada desde la atalaya del aillu de Túpac Yupanqui y sus desposeídos descendientes.

El Garcilaso adolescente «entrava y salía muchas vezes donde ellos [Chimpu Ocllo y sus parientes] estavan [conversando]» y se solazaba oyéndolos. Si bien los temas frecuentados eran distintos -el origen, la majestad y grandeza, las conquistas, hazañas y leyes y el gobierno en paz y guerra-, su común denominador fue la historia antigua de los incas. Invariablemente, «con la memoria del bien perdido siempre acabavan su conversación en lágrimas y llanto, diziendo: “Trocósenos el reinar en vassallaje"» $(C R, 1$, libro 1 , cap. 15, 40). Así, la presencia de Chimpu Ocllo, el ámbito del hogar materno y las pláticas allí efectuadas marcan la crónica ofreciendo una singular perspectiva discursiva e ideológica donde conviven oralidad y escritura, el punto de vista femenino (pallas) y el masculino (incas), el esquema conceptual de

5 El narrador comenta: «Passando pues días, meses y años, siendo ya yo de diez y seis o diez y siete años...» $(C R, 1$, libro 1 , cap. 15, 40). 
un sector de la realeza incaica (en el recuento del pasado) y el de los preceptos de la cultura europea (en la fijación y reordenación de los hechos evocados). Todo ello lo asimiló Gómez Suárez, quien cuenta lo que en sus «niñezes» escuchó de su madre, tíos y señores ancianos (CR, 1, libro 1, cap. 15, 39).

Las voces de Chimpu Ocllo y de sus familiares que el joven oía en el hogar materno del Cuzco en el curso de los años, se constituyen en un murmullo soterrado y polifónico que fundamenta la crónica y anuncia su trágico trazo tal y como lo resume el citado lamento: «Trocósenos el reinar en vassallaje». Como ya se observó refiriéndose a la Historia general del Perú (Durand 1976; Zanelli 2007), el cronista cuzqueño plasma en su texto elementos propios de la tragedia y de la historiografía; este razonamiento, en mi concepto, es igualmente aplicable a la primera parte de la crónica, también entendible como tragedia en el sentido de la representación de personajes «graves», dioses, héroes, reyes y príncipes, «rematada» por una gran desgracia (Covarrubias c. 1979 [1611]). Así, los eventos mayores de ambas partes de la obra —el asesinato de Huáscar ordenado por su medio hermano, las crueldades de Atahualpa, su «ajusticiamiento» por parte de los conquistadores, la decapitación de Túpac Amaru, el fin del incario, la imposición del coloniaje- aludidos por estas voces narrativas al comienzo de la crónica, y elaborados y justipreciados después, nos conducen a la desdicha de ese linaje y a la vez afirman sus bondades. Más tarde, la figura de Chimpu Ocllo se imbrica en otros sucesos de la historia del virreinato peruano los cuales igualmente contribuyen a dramatizar el aspecto trágico de 
Comentarios reales y a afirmar la valía y copresencia del binomio madre/hijo, así como de la familia andina del autor. Veamos un importante episodio relacionado con las guerras civiles del Perú.

\section{El socorro de los parientes}

Cuando el narrador se ocupa de las luchas fratricidas entre los conquistadores, Chimpu Ocllo se representa como protectora de su familia y leal al bando realista. Ya en plena rebelión de Gonzalo Pizarro contra la imposición de las Nuevas Leyes, cuando Gómez Suárez tenía apenas cuatro años, la casa paterna es cercada y atacada por el rebelde Hernando Bachicao (1542). El capitán Garcilaso, quien había apoyado a Gonzalo Pizarro al comienzo de la rebelión, escapó a Lima cuando se dio cuenta del nuevo sesgo de esta, y su casa cuzqueña quedó desamparada ${ }^{6}$. Según comenta el narrador, la noche del ataque allí se congregaban ocho personas: Chimpu Ocllo, Gómez Suárez, su hermana, dos ayudantes indígenas, el ayo Juan de Alcobaza y sus dos hijos. En los ocho meses de asedio, el grupo hubiese muerto de hambre si no hubiera recibido el socorro de «Incas y Pallas parientes, que a todas las horas del día nos embiavan por vías secretas algo que comer», y del curaca don García Pauqui, cuyo nombre, en admiración por su lealtad, el cronista consigna $(H G, 2$, libro 4, cap. 10, 39). En momento tan crucial, la familia se salva

\footnotetext{
6 El padre del autor y otros conquistadores habían ido a Arequipa con la idea de viajar por mar a Lima y unirse al virrey y al grupo leal a la Corona. El narrador ofrece detalles de esta peripecia y explica por qué fallaron estos planes; en todo momento salvaguarda a su padre de la acusación de traición (HG, 2, libro 4, cap. 10, 37).
} 
gracias a la generosidad de este curaca y de los deudos maternos - la operante genealogía- dispuestos a arriesgar vida y bienes por la princesa y sus hijos. De este modo la presencia de la madre y la importancia de su aillu se reconocen en el enlace salvífico gracias al cual la familia evade el hambre, conserva el hogar y sobrevive el cerco de los rebeldes.

En un nivel más profundo, el episodio le sirve al narrador para resaltar la fidelidad a la Corona de ambos progenitores y también de los parientes de la palla que, a riesgo de perder la vida y su hacienda a manos de los gonzalistas, apoyan a los asediados y toman partido por el rey en tiempos tan precarios. Como ya señalé, el narrador destaca cuánto aprecia la lealtad de don García Pauqui, y asimismo resalta el carácter caballeresco de esta virtud. Además de proyectar de forma positiva y real las redes de parentesco y la presencia materna, el episodio realza la conducta de súbditos andinos tan leales a la Corona - en contraste con los rebeldes españoles- como nobles. Seguramente su participación en la administración del virreinato, parece insinuar la voz narrativa, es deseable; la intervención de este grupo de parientes del linaje materno del autor en la administración del Perú, augura tanto éxito como se evidenció en su comportamiento descrito en el episodio comentado.

\section{La relevancia del linaje}

Igualmente significativo en cuanto a la copresencia materna, es el episodio del capítulo once del libro octavo de la segunda parte de Comentarios reales donde el narrador describe la llegada al Cuzco (c. 1559) de Sayri Túpac, el inca rebelde que abandonó el reducto 
de Vilcabamba y pactó con el virrey Andrés Hurtado de Mendoza, marqués de Cañete (ilustración 1). En la antigua capital del Tahuantinsuyo «todos los de su sangre real, hombres y mujeres, acudieron a besarle las manos y darle la bienvenida a su imperial ciudad. Yo fui en nombre de mi madre a pedirle licencia para que personalmente fuera a besárselas» $(H G, 3$, libro 8 , cap. 11, 212). Por medio del posesivo «mi», el narrador resalta el vínculo materno a la prestigiosa prosapia del inca vilcabambino; también por medio de otro adjetivo posesivo - el Cuzco es «su» imperial ciudad- le otorga al soberano el dominio virtual sobre la urbe que otrora le hubiera correspondido regir. La respuesta de Sayri Túpac al joven Gómez Suárez no se hace esperar: «Dile a mi tía que le beso las manos, y que no venga acá, que yo iré a su casa a besárselas y darle la norabuena de nuestra vista» $(H G, 3$, libro 8, cap. 11, 213). El encuentro inicial de Sayri Túpac con Gómez Suárez, el deseo del inca de que el joven hubiera integrado la comitiva de recepción y su réplica ante la solicitud de permiso de Chimpu Ocllo para visitarlo y rendirle pleitesía, ratifican la pertenencia de madre e hijo al más alto linaje; al mismo tiempo, anuncia la relevancia de Sayri Túpac - gracias a su decisión se ha logrado la paz- para un futuro armonioso en el recién establecido virreinato peruano (1542).

Por medio de la figura del soberano vilcabambino, el narrador pone en evidencia la ambigua situación de la nobleza incaica en la nueva sociedad: antes Sayri Túpac fue señor del incario y ahora es súbdito de la Corona española. De ahí la alternancia de alegría y tristeza entre sus vasallos andinos - gran gozo de ver 
al príncipe; inmenso dolor al asumir tanta pérdida-. Tal fluctuación, por otra parte, ya la hemos visto en las conversaciones iniciales entre la madre y los parientes, cuando estos pasan del júbilo al quebranto al recordar las grandezas pasadas, contemplar el presente estrago y asumir su condición de vasallos. Por otro lado, la alusión a la madre y su parentesco con el inca destronado nuevamente le da entrada al joven a un ámbito real y especial. En este episodio predomina la figura materna por medio de la cual el autor de Comentarios reales reafirma su pertenencia a la cultura de la élite incaica. Que el relato de hechos tan significativos culmine con la anticipación del «fin y muerte» de Sayri Túpac en menos de tres años $(H G, 3$, libro 8, cap. 11, 214), tiñe de aflicción el episodio y acentúa el fatídico destino de la estirpe.

Si bien el nombre materno y la compartida genealogía le permiten al joven Gómez Suárez ingresar a un ámbito reservado y allí regocijarse con sus parientes, la destruida capital donde se desarrolla la bienvenida a Sayri Túpac deviene en trágico teatro cuya coreografía la conforman destartaladas edificaciones incaicas; así, el gozo del encuentro está aureolado por un clima y un espacio ruinoso. Todo ello se hace evidente porque es textualmente posible comparar el estado de las construcciones en el momento del arribo de Sayri Túpac al Cuzco con anteriores descripciones de estas durante el apogeo del incario, cuando su magnificencia afirmó la grandeza del imperio y despertó la admiración de los europeos ${ }^{7}$.

7 Véase $C R, 2$, libro 7, caps. 27-29. 
En el contexto de la llegada de Sayri Túpac al Cuzco, la conexión de la madre y del hijo con el aillu de Túpac Inca Yupanqui y de Huáscar se reafirma cuando el narrador comenta cómo un español (Miguel Astete o Estete) le obsequia al soberano la mascapaycha o borla colorada, símbolo de los reyes incas, y este la acepta con fingido regocijo. Después nos enteramos de que, por haberle pertenecido a Atahualpa, todos consideraron la borla odiosa, abominaron de ella y aconsejaron quemarla. En el relato del incidente, aflora entonces la enemistad entre los aillus reales y el conflicto propiciador del fin del incario. El narrador así lo confirma cuando observa:

que por haver hecho Atahuallpa la traición, guerra y tiranía al verdadero Rey, que era Huáscar Inca, havía causado la pérdida de su Imperio. Por tanto devía quemar la borla, por haverla traído aquel auca traidor, que tanto mal y daño hizo a todos ellos. Esto y mucho más contaron los parientes a mi madre cuando vinieron al Cozco (HG, 3, libro 8, cap. 11, 212).

Igualmente, la anécdota se sobredimensiona al reiterar otra posible explicación de la derrota del incario: ocurrió por rivalidades internas y no por la superioridad de las armas españolas. Además, reitera la pertenencia de madre e hijo al clan de Huáscar ratificando así la alta prosapia de la princesa y de su heredero, el joven Gómez Suárez de Figueroa. De este modo nos percatamos nuevamente de los singulares matices que la presencia o la evocación de la madre le otorga a la estructura de la crónica. Por un lado, sirve de puente al pasado glorioso rememorado por el narrador y fundamentado en 
la voz de Chimpu Ocllo, del tío, de pallas e incas; en otras palabras, en la oralidad andina que socava la historia oficial y nos remite a la época del pre-contacto; por otro lado, la mención de la madre trae al presente - o sea, al tiempo del relato- la llaga familiar, la traición de Atahualpa, el asesinato de Huáscar, el fin de su clan y los eventos favorecedores de la entrada española en el Cuzco. En este sentido, y reafirmando el tono trágico evidente en la conclusión de la primera parte de Comentarios reales, es pertinente notar cómo los capítulos finales se centran en las crueldades de Atahualpa contra los familiares de Huáscar y en cómo Chimpu Ocllo logra salvarse de esta masacre.

\section{La descendencia de Huáscar}

En efecto, los seis últimos capítulos del libro nueve de la primera parte de la obra maestra del Inca Garcilaso se ocupan de estos desdichados sucesos. El capítulo treinta y siete es el más dramático del sector y asimismo el más pertinente a nuestra propuesta. En este el narrador cuenta detalladamente cómo las mujeres y los niños de la sangre real de Huáscar fueron apresados, torturados y asesinados. De ahí, acota el narrador, la extinción ${ }^{8}$ de gran parte del linaje de los incas en un lapso de dos años y medio, y «aunque pudieron acabarla en más breve tiempo, no quisieron, por tener en quién exercitar su crueldad con mayor gusto» $(C R, 2$, libro 9, cap. 37, 290). Se llevaron a las mujeres y los niños a Yahuarpampa o campo de sangre, el mismo paraje

8 Sabemos que el linaje no fue extinguido y así se indica en otra parte $(C R, 2$, libro 9, cap. 38, 290-291, y cap. 40, 295-297). 
donde antes habían combatido antiguos enemigos, los chancas y los cuzqueños ${ }^{9}$. Este nombre se afirma en la narración por la cantidad y calidad de los muertos, particularmente por la «mayor lástima y compassión» causadas «por la tierna edad de los niños y naturaleza flaca de sus madres» (CR, 2, libro 9, cap. 37, 290).

Según explica el narrador, los prisioneros estaban custodiados por medio de tres cercos, el primero de gente de guerra, y los otros dos de centinelas; a las mujeres y a los niños se les asesinó periódicamente de hambre y por medio de varios tormentos. Con todo, los soldados de Atahualpa, «de lástima de ver perecer la sangre que ellos tenían por divina, cansados ya de ver tan fiera carnicería» (CR, 2, libro 9, cap. 38, 290), sacaron del cerco a algunos prisioneros, niños y niñas menores de once $o$ diez años, les quitaron los vestidos reales y les pusieron los de la gente común. Con esta ayuda lograron escapar la madre del Inca y un hermano suyo, don Francisco Huallpa Túpac Inca Yupanqui, futuro corresponsal del autor. Otra vez, lo contado por testigos y sobrevivientes de los terribles sucesos, le otorga singular autoridad al narrador para referirlos: «y de la relación que muchas vezes les oí es todo lo que desta calamidad y plaga voy diziendo» (CR, 2, libro 9, cap. 38, 290). Las torturas y las muertes tan vívidamente descritas apuntan al funesto destino de la estirpe; respectivamente, el comentario atribuido a los centinelas y el cambio de traje de Chimpu Ocllo niña destacan la alta prosapia de las víctimas tanto como la importancia del atuendo en el incario

Se cree que ocurrió en 1438; algunos cronistas le atribuyen el triunfo a Pachacútec, otros a Viracocha (Inca Garcilaso). A raíz de la derrota chanca, el Tahuantinsuyo se consolida y expande bajo el Inca Pachacútec. 
- recordemos la centralidad de los tejidos de cumbi y la vestimenta del soberano confeccionada por las vírgenes del Sol— ${ }^{10}$. Igualmente, la actitud generosa de los centinelas, quienes, horrorizados ante la cantidad y calidad de la sangre vertida, permiten la fuga de algunas de las víctimas, contrasta con la cruel conducta de Atahualpa y a la vez permite aproximar una pregunta cara al narrador: ¿dónde reside la nobleza, en la conducta o en el linaje? Así, por medio del testimonio, de la oralidad convocada por la presencia de la madre y de los familiares andinos del autor, nos acercamos a ese pasado lejano y violento desde cuya atalaya avizoramos el calamitoso fin del Tahuantinsuyo.

Que todo ello haya acontecido en Yahuarpampa, a la vista de tantos, nos lleva a la gran plaza del Cuzco donde, años después (1572), tendrá lugar la decapitación de Túpac Amaru (ilustración 2), presenciada por una mixta muchedumbre de españoles e indígenas, y descrita al final de la segunda parte de Comentarios reales (libro 8, capítulo 19). Ambos hechos (el de Yahuarpampa y el del Cuzco) se sitúan al final de cada parte de la obra. Se presentan como crueles espectáculos con diferentes responsables (Atahualpa y el virrey Toledo), víctimas de similar procedencia (la realeza incaica) y consecuencias mayores (el fin de una dinastía y de un imperio). En Yahuarpampa quienes perpetran la matanza contra los parientes de Garcilaso

\footnotetext{
10 Sobre esto Garcilaso comenta: «ellos mimos los echavan fuera, quitándoles los vestidos reales y poniéndoles otros de la gente común, por que no los conociesen; que, como queda dicho, en la estofa del vestido conocían la calidad del que lo traía» $(C R, 2$, libro 9, cap. 38, 290). Sobre la importancia del atuendo ver Phipps 2004 y Ramos 2010.
} 
son del bando de Atahualpa; en el Cuzco, quien ordena la ejecución de Túpac Amaru ${ }^{11}$, el inca vilcabambino, es el virrey Toledo. De este modo el narrador equipara el comportamiento de Atahualpa con el del virrey Toledo: la conducta del primero causa la escisión del Tahuantinsuyo, elimina su más preclaro linaje real y propicia el triunfo español. El accionar del segundo muestra el sesgo trágico de la invasión europea en el mundo andino en la persona del soberano decapitado y también afirma el dominio español en la zona. Ambos, el inca usurpardor (Atahualpa) y el atrevido virrey (Toledo), son expuestos como catalizadores de la tragedia, como enemigos del grupo familiar al cual pertenecen Chimpu Ocllo, víctima y sobreviviente de estos sucesos, y el Inca Garcilaso de la Vega, quien ahora los cuenta y reinterpreta.

\section{La muerte del auca}

La presencia de la madre se observa nuevamente en el capítulo treinta y nueve del libro nueve de la primera parte de Comentarios reales, con motivo de la muerte de don Francisco, uno de los hijos de Atahualpa, a quien, como a su padre, los familiares motejaban de $a u c a^{12}$. A raíz de este fallecimiento, el inca viejo cuyos relatos de las glorias del Tahuantinsuyo tanto impresionaron a Gómez Suárez de Figueroa ${ }^{13}$, visita a Chimpu Ocllo para darle el «plázeme» por la muerte del pariente y le desea

\footnotetext{
11 Fue el último de los incas del reducto andino de Vilcabamba, apresado y llevado en cadenas al Cuzco.

12 Enemigo o traidor (González Holguín 1952 [1608]).

13 Véase, por ejemplo, CR, 1, libro 1, caps. 15 y 19.
} 
«que el Pachacámac la guardasse muchos años, para que viesse la muerte y fin de todos sus enemigos, y con esto dixo otras muchas palabras semejantes con gran contento y regozijo». Ante el jolgorio, el joven hijo de la palla le pregunta sorprendido al tío: «Inca ¿cómo nos hemos de holgar de la muerte de Don Francisco, siendo tan pariente nuestro?». Este le responde con rabia, reitera el calificativo de tirano al referirse al difunto, niega que sea descendiente de Huayna Cápac ${ }^{14}$ y hasta ofrece comérselo «assí muerto, como está,... crudo, sin pimiento» (CR, 2, libro 9, cap. 39, 294). Seguidamente presenta el código por el cual se regía el inca gobernante:

la doctrina de nuestros passados nunca fué que hiziéssemos mal a nadie, ni aun a los enemigos, cuanto más a los parientes, sino mucho bien a todos... mira que a ellos y a nosotros y a ti mesmo te hazes mucha afrenta en llamarnos parientes de un tirano cruel, que de Reyes hizo siervos a essos pocos que escapamos de su crueldad ( $C R$, 2, libro 9, cap. 39, 294-295).

En el recuento de este suceso nos enteramos de que era tan grande el odio que las familias reales y los indios todos tenían hacia don Francisco y sus dos hermanas que estos no se atrevían a salir de casa porque todos los motejaban de auca, «tan significativo de tiranías, crueldades y maldades, digno apellido y blasón de los que lo pretenden» $(C R, 2$, libro 9, cap. 39, 295). En un aprovechamiento del antiguo topos del «mundo al

14 El inca viejo explica: «Aquel traidor de Atahuallpa, su padre, no era hijo de Huaina Cápac, nuestro Inca, sino de algún indio Quitu con quien su madre haría traición a nuestro Rey; que si él fuera Inca, no sólo no hiziera las crueldades y abominaciones que hizo, mas no las imaginara» $(C R, 3$, libro 9, cap. 39, 294). 
revés», el "plázeme» —que no el pésame- ofrecido a Chimpu Ocllo por el tío con motivo del fallecimiento del «pariente», da otra vuelta de tuerca: la alegría por la muerte del familiar traidor se troca en llanto cuando los sobrevivientes recuerdan las crueldades de Atahualpa y cómo, a consecuencia de su conducta, pasaron de ser señores a ser vasallos.

La presencia de la madre sirve aquí para de nuevo vilipendiar a Atahualpa y sus descendientes, afirmar su carácter de tirano y exaltar al incario por medio de la exposición del perfecto código al cual se adherían sus soberanos; como es de esperarse, tal encumbramiento de los antiguos gobernantes lleva implícita la crítica al coetáneo coloniaje. Al mismo tiempo, el episodio acentúa el pathos de la narración creando un sentimiento de rechazo hacia Atahualpa y sus descendientes, y también hacia quienes no siguen las normas asociadas con el buen gobierno propuesto por los incas. Es igualmente instructivo observar cómo el narrador retorna al intercambio con el tío, suscitado por otra visita suya a casa de Chimpu Ocllo. De este modo se ratifica en este capítulo final de la primera parte de los Comentarios reales el lamento inicial de los deudos maternos: «Trocósenos el reinar en vassallaje» $(C R, 1$, libro 1 , cap. 15,40$)$. Que en ambas instancias este clamor haya surgido en el contexto de visitas a la casa materna en el Cuzco y de las conversaciones allí sostenidas, muestra el peso de la palla y de su genealogía tanto en la formación inicial del autor como en la constitución del estatuto trágico de la obra, anunciado en sus primeros capítulos y afirmado después en los apartados finales de la primera y segunda parte de la crónica. 
La presencia de la madre - ya fugaz, ya opaca- en Comentarios reales es mucho más importante de lo hasta ahora comentado por la crítica. Por medio de ella, de las pláticas sostenidas por el joven Gómez Suárez de Figueroa con Chimpu Ocllo, los incas y las pallas, es posible apreciar el intercambio intergenérico e intercultural en la formación del autor; al mismo tiempo, el modo de presentar la historia incaica y la variedad de temas tratados en estas conversaciones ofrecen el fundamento de la obra y le otorgan a ambas partes su cariz trágico. Todo ello trasciende en episodios donde se evoca la presencia materna o esta aparece como figura secundaria pero catalizadora de la acción. Por ejemplo, el episodio sobre el asalto a la casa cuzqueña del capitán Garcilaso de la Vega durante las guerras civiles, muestra la fidelidad a la Corona de sus ocupantes y de los parientes incas; también sirve para afirmar la cuestionada lealtad del capitán, la estabilidad de la unión entre este y la princesa y la solidez de los lazos familiares maternos en tiempos muy cambiantes. La llegada al Cuzco de Sayri Túpac después de pactar con las autoridades españolas, reitera la alta prosapia de madre e hijo. A la vez, el episodio muestra el odio entre Huáscar y Atahualpa, y perfila una diversa explicación de la derrota del incario basada en estas rivalidades. Por otro lado, si bien en este recuento la precariedad de las edificaciones incaicas exhibe la ruina del Tahuantinsuyo en su capital, la voz de la madre y los parientes nos lleva a su pasado glorioso; en este sentido, la reiteración de varias 
alternancias (pasado/presente; riqueza/decadencia; soberano/vasallo; benignidad/maldad) implica la presencia materna en la estructura de la crónica y la tiñe de quebranto.

Los capítulos finales de la primera parte de Comentarios reales relatan las crueldades de Atahualpa con sus familiares. El apartado relacionado con la fuga de la madre en atuendo muy común nos la muestra como víctima, testigo y relatora indirecta de tales sucesos. El trágico teatro de estos acontecimientos igualmente remite a un hecho de gran envergadura: la muerte de Túpac Amaru en la plaza del Cuzco, suceso que anuncia el fin del incario y la consolidación del dominio español. Estas acciones, ordenadas respectivamente por Atahualpa y el virrey Toledo, permiten equiparar al mal soberano y al mal virrey, enlazar las dos partes de la obra y ratificar su factura trágica. Narrado en el contexto de otra visita del tío a casa de Chimpu Ocllo, el relato de la muerte de don Francisco, el hijo de Atahualpa, condena la tiranía de ese gobernante $\mathrm{y}$, al exaltar el buen gobierno de los soberanos incas, acentúa la distancia entre los clanes y contrasta dos épocas (el incario y el coloniaje) donde la crítica recae sobre la segunda. De nuevo, el episodio liga el desenlace de las dos partes de Comentarios reales cuando Chimpu Ocllo y sus parientes conjuntamente reiteran la tragedia del clan y cómo el reinar se les trocó en vasallaje. Vista desde esta perspectiva, la madre, orgullosamente evocada o fugazmente presente, no es mera sombra sino pilar principal en el entramado ideológico y el significado profundo de la reformulación de la historia patria evidente en Comentarios reales. 


\section{Anexos}

Ilustración 1

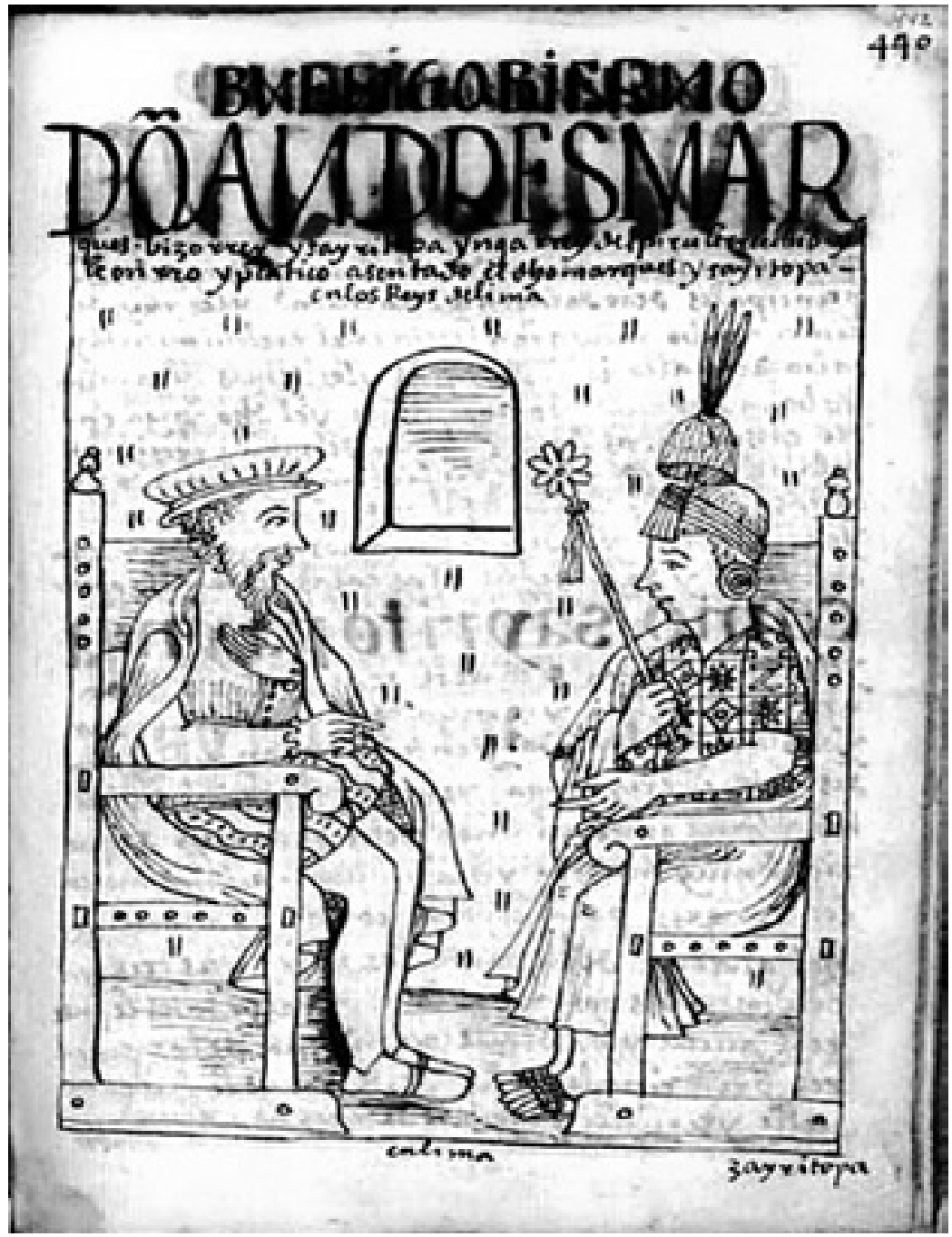

Sayri Túpac y el virrey Hurtado de Mendoza conversando en Lima. Felipe Guaman Poma de Ayala, Primer nueva corónica y buen gobierno (1615). GKS 4 . $^{\circ}$ Cortesía de la Biblioteca Real de Copenhague, Dinamarca. 


\section{Ilustración 2}

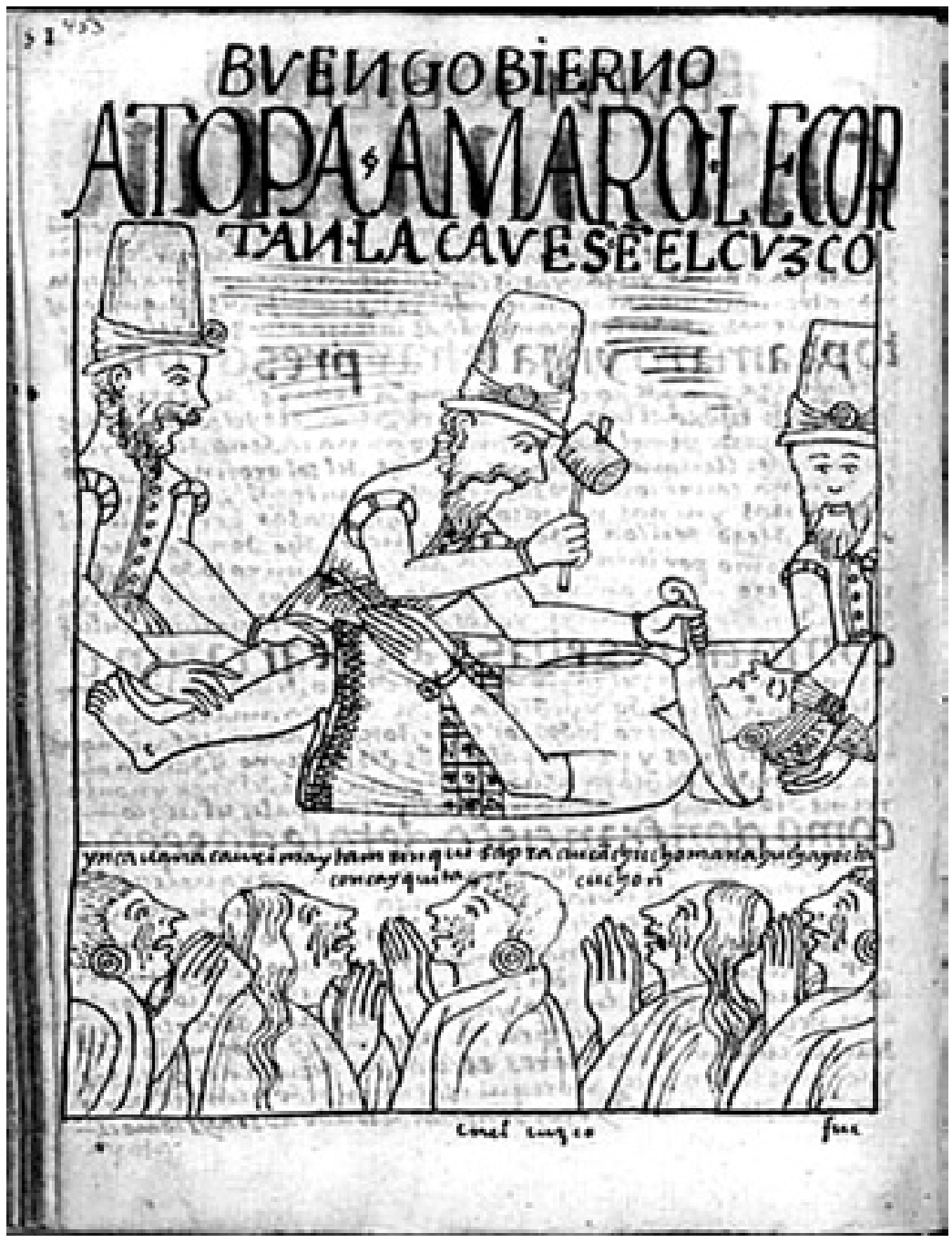

La decapitación de Túpac Amaru en la plaza del Cuzco (1572). Felipe Guaman Poma de Ayala, Primer nueva corónica y buen gobierno (1615). GKS $4 .^{\circ}$. Cortesía de la Biblioteca Real de Copenhague, Dinamarca. 


\section{Bibliografía}

CHANG-RODRÍGUEZ, Raquel. Cartografía garcilasista. Alicante, Universidad de Alicante, 2013.

COVARRUBIAS, Sebastián de. Tesoro de la lengua castellana o española. Madrid, Turner, 1979 [1611].

DURAND, José. El Inca Garcilaso, clásico de América. México, SepSetentas, 1976.

GARCILASO DE LA VEGA, Inca. Comentarios reales. Ed. de Ángel Rosenblat con prólogo de Ricardo Rojas. 2 vols. Buenos Aires, Emecé, 1943 [1609].

. Historia general del Perú.

Ed. de Ángel Ronseblat con prólogo de Ricardo Rojas. 3 vols. Buenos Aires, Emecé, 1944 [1617].

GONZÁLEZ DE HOLGUÍN, Diego. Vocabvlario de la lengva general de todo el Perv llamada lengua qquichua o del Inca. Prólogo de Raúl Porras Barrenechea. Lima, UNMSM, 1952 [1608].

GUAMAN POMA DE AYALA, Felipe. Primer nueva corónica y buen gobierno. Ed. crítica de John V. Murra y Rolena Adorno. Traducciones y análisis textual del quechua de Jorge L. Urioste. 3 vols. México, Siglo XXI, 1980 [1615].

HERNÁNDEZ, Max. Memoria del bien perdido. Conflicto, identidad y nostalgia en el Inca Garcilaso de la Vega. Lima, Instituto de Estudios Peruanos, 1993.

HERNÁNDEZ ASTETE, Francisco. «Las panacas y el poder en el Tahuantinsuyo", en Boletín del IFEA. 37, 1, Lima, 2008, págs. 29-45. 
ITIER, César. «Las panacas no existieron», en ADELAAR, William y otros. Estudios sobre lenguas andinas y amazónicas: Homenaje a Rodolfo Cerrón-Palomino. Lima, Fondo Editorial Pontificia Universidad Católica del Perú, 2011, págs. 181-194.

LÓPEZ-BARALT, Mercedes. El Inca Garcilaso, traductor de culturas. Madrid, Iberoamericana/Vervuert, 2011.

MIRÓ QUESADA, Aurelio. El Inca Garcilaso. Lima, Pontificia Universidad Católica del Perú, 1994.

PHIPPS, Elena. «Garments and Identity in the Colonial Andes», en The Colonial Andes. Tapestries and Silverwork, 15301830. Ed. Elena Phipps y otros. New York/New Haven, The Metropolitan Museum/Yale University Press, 2004, págs. 17-39.

RAMOS, Gabriela. «Los tejidos y la sociedad colonial andina", en The Power of Images: Visual Representation in New Spain and Peru. Ed. Nancy Farriss. Special Issue of Colonial Latin American Review. 19.1. 2010, págs. 115-149.

USPENSKI, Boris. A Poetics of Composition. The Structure of the Artistic Text and Typology of a Compositional Form. Trads. Valentina Zavarin y Susan Wittig. Berkeley, University of California Press, 1973.

ZANELLI VELÁZQUEZ, Carmela. «Significados, acepciones y variaciones: usos contradictorios del concepto de "tragedia" en los Comentarios reales del Inca Garcilaso de la Vega», en Lexis: Revista de Lingüística y Literatura. Vol. 31. No 1-2. Lima, 2007, págs. 391-402. 